\title{
BIOLOGY AND LIFE TABLE PARAMETERS OF THE COCCINELLID PREDATORY INSECT Stethorus gilvifrons (MULSANT) FED ON IMMATURES OF Tetranychus urticae ( $\mathrm{KOCH})$
}

Nassar, O. A.; A. H. Fouly and M. A. Osman

Agricultural Zoology Department, Faculty of Agriculture, Mansoura University, Mansoura 35516, Egypt. mesoma20@mans.edu.eg

\begin{abstract}
Biological aspects of the predatory insect Stethorus gilvifrons (Mulsant) fed on nymphs of the two - spotted spider mite Tetranychus urticae Koch were studied in laboratory at $25 \pm 1{ }^{\circ} \mathrm{C}$ and $70 \pm 5 \% \mathrm{RH}$., Egg incubation period of eggs lasted 3.87 and 4.07 days for male and female, respectively. The first female larval instar was active stage lived for about 2.93 days, during which it consumed and $7.73 \mathrm{~T}$. urticae individuals with a daily rate of 2.64 preys / day. The same trend was noticed within the second larval instar that lived for a shorter time 2.00 days and consumed 14.80 preys with a daily 7.40 preys. The third larval instar lived for 2.33 and consumed 25.46 with a daily rate of 10.92 preys / day. The fourth instar lasted 4.13 days during which it consumed 69.40 with daily rate of 16.80 prey individuals. Pupal stage lasted for 3.73 and 4.47 days for male and female, respectively. Life cycle durated 17.70 and 19.90 days for male and female, respectively.

Average male and female longivety was 24.33 and 36.46 days, respectively. Data showed that adult female of $S$.gilvifrons, which lived 36.46 days, consumed a total number of $T$. urticae nymphs 2267.13 prey nymphs / female .

Thus, adult female consumed during its oviposition period and longevity nearly $77.0 \%$ and $95 \%$ of the total consumed prey during its whole life span. The mean generation time $(T)$ averaged 30.41 days. Net reproductive rate $\left(R_{0}\right)$ was 49.53 and the intrinsic rate of natural increase $\left(r^{\mathrm{m}}\right)$ was 0.12 , the finite rate of increase $e^{r m}$ $(\lambda)$ was 1.13 .
\end{abstract}

Keywords : Tetranychus urticae - Stethorus gilvifrons - biology - life table

\section{INTRODUCTION}

The two - spotted spider mite Tetranychus urticae Koch is considered to be the most dangerous species of the family of tetranychidae. It is difficult to manage this group of mite pests by chemical compounds because a kind of resistance can be developed within a few years (Geoghiou, 1990). Therefore, it was necessary to develop some other control tactics such the use of biological control agents.Predatory mites especially the mesostigmatid mites are considered to be among the most promising bioagent of spider mites. Apart from the predatory mites, some insects are also known to have the ability to be natural enemies of spider mites. Predatory thrips, lady bugs and staphylinid species have been recognized as promising predators of spider mites (Gilstrap, 1995; Kishimoto, 2003 and Roy et al. 2003). The predaceous insects such as Stethorus species Weise (Coccinellidae: Coleoptera) are acariphagous where they feed successfully on spider mites (Kishimoto, 2003). All known species of this genus have been suggested to have potentiality as biological control agents of spider mites 
(Baily and Caon, 1986; Felland and Hull, 1996; Rott and Ponsonby, 2000 and Ragkou et al., 2004). However, given that this genus may have certain advantages as a potential biocontrol agent, further experiments are essential, in order to assess the feasibility of their use for mite control under the Egyptian local conditions. Therefore the present work aims to study all biological aspects during the whole life span of Stethorus gilvifrons Mulsant

\section{MATERIAL AND METHODS}

the predaceous coccinellid Stethorus gilvifrons (Mulsant) were colleted from leaves and twigs of castor plants Ricinus communis growing at the farm of the Faculty of Agriculture, Mansoura University, Mansoura district. Samples of plant leaves and twigs were collected in Polyethylene bags, with small pieces of cotton wool soaked in ether and brought to the laboratory for direct examination using a stereoscopic binocular microscope.

The adults of predaceous coccinellid $S$. gilvifrons were kept in plastic boxes $20 \mathrm{~cm} \times 10 \mathrm{~cm} \times 5 \mathrm{~cm}$ coverd with muslin on the top and the bottom covered with filter paper as shown in Fig.1. The box was provided with pieces of leaves of castor plants Ricinus communis which heavily infested with the spider mites Tetranychus urticae Koch as a source of sufficient food.
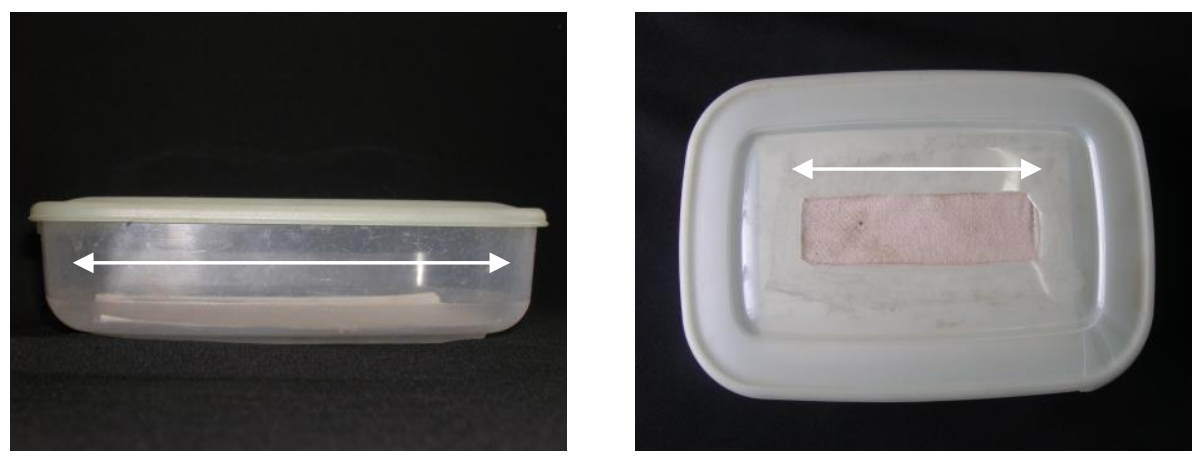

Fig. (1): Mass rearing unit for the predatory insects Stethorus gilvifrons preying immature of $T$. urticae.

\section{Biological studies of Stethorus gilvifrons (Mulsant)}

The predaceous coccinellid Stethorus gilvifrons ( Mulsant) was colleted from leaves of castor plants $R$. communis and provided with nymphs of Tetranychus urticae as a source of food. Tetranychid mites were collected from leaves of castor plants at Mansoura district.

Predaceous coccinellid $S$. gilvifrons was kept in an incubator at $25 \pm 1^{\circ} \mathrm{C}$ and $70 \pm 5 \% \mathrm{RH}$., where the newly emerged females deposited its eggs.

The newly deposited eggs were singly transferred to small plant leaf discs of Hibiscus mutabilis (1 inch each) placed on moist cotton pad in Petri dishes $(15 \mathrm{~cm}$ in diameter). The cotton pad was supplied with moisture to keep leaf discs fresh and also to prevent immature individuals of coccinellid from escaping. Pupae were kept separately in plastic tubes $(2 \times 10 \mathrm{~cm})$ Fig. 2, its 
opening covered with pieces of muslin and a small piece of the tube wall $(1 \times$ $1 \mathrm{~cm}$ ) was cut and covered with piece of muslin to keep suitable humidity. After emergance of the adult insects, they were coupled ( $q$ \& $\delta^{\lambda}$ ) and each kept in a tube provided with pieces of castor plant leaves heavily infested with the immature of spider mites $T$. urticae as a source of food.
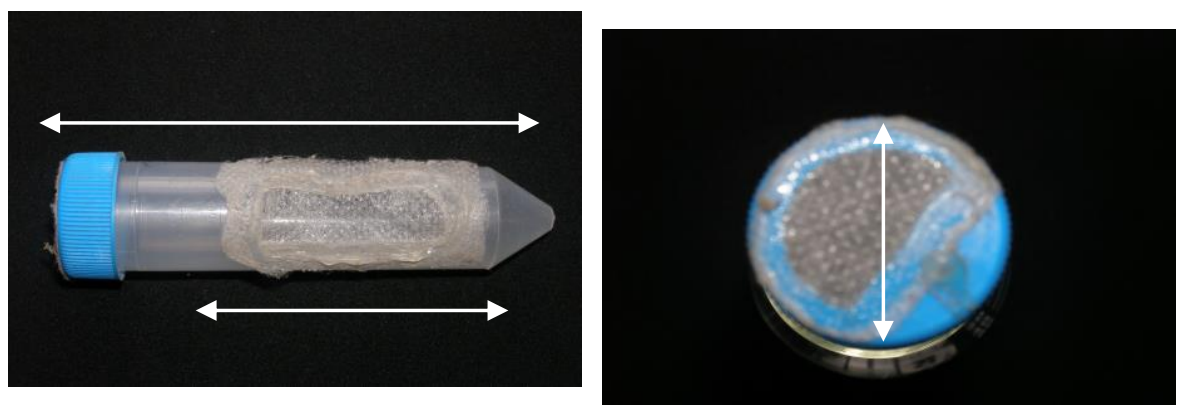

Fig. (2): Rearing unit for the predatory insect adult Stethorus gilvifrons preying immature of $T$. urticae with opening on upper and lateral side of the tube covered with muslin for aeration.

Data were recorded for the whole life span, where observations were noted twice daily. The rearing experiment was started with 20 newly hatched larvae.

Individual development, survival and egg production of adult females were observed where life table parameters were calculated according to Birch (1948), Laing (1968) and using the Basic Computer Program of Abou Setta and Childers (1986), where:-

$\begin{array}{lll}\mathbf{L} & : & \text { Number of females alive. } \\ \mathbf{X} & : & \text { Actual female age. } \\ \mathbf{M}_{\mathbf{X}} & : & \text { Femal progeny / female. } \\ \mathbf{L}_{\mathbf{x}} & : & \text { Rate of survival (survivorship). } \\ \mathbf{R}_{\mathbf{0}} & : & \text { The net reproductive rate. } \\ \mathbf{T} & : & \text { The mean generation time. } \\ \mathbf{R}_{\mathbf{m}} & : & \text { Interinsic rate of natural increase. } \\ \mathbf{e}^{\mathrm{rm}} & : & \text { Finite rate of increase. }\end{array}$

\section{RESULTS AND DISCUSSION}

In a preliminarily study, it was found that Stethorus gilvifrons failed to develop when kept at $20^{\circ} \mathrm{C}$ under laboratory conditions and provided with its common prey Tetranychus urticae. Therefore, individuals of this predatory insect species were reared at the most suitable temperature for most arthropods, $25{ }^{\circ} \mathrm{C}$ in an incubator to know as much as we can about its biology. 
Nassar, O. A. et al.

Similarly, Roy et al., (2003) failed to get a good development from S. punctillum Weise, which was provided with Tetranychus mcdanieli McGregor kept at $16-18^{\circ} \mathrm{C}$.

However, data listed in Table (1) showed that egg incubation period averaged 3.87 and 4.07 days for male and female, respectively. The first female larval instar was an active stage that lived for about 2.93 days, during which it consumed 7.73 T.urticae nymphs with a daily rate of 2.64 preys / day as shown it Tables 1, 2 and Figs 3, 4.

The second larval instar lived for a shorter time 2.00 days and consumed 14.80 prey individuals with a daily rate of 7.40 nymphs. The third larval instar lived for 2.33 and consumed 25.46 with a daily rate of 10.92 mite nymphs / day (Tables 1, 2).

Data also showed that the fourth larval instar lived for a longer time and consumed more prey than former ones. It lasted 4.13 days during which consumed 69.40 with a daily rate of 16.80 nymphs as shown in Figs ( $3 \& 4$ ) and $($ Tables 1,2$)$.

When full grown, larvae of $S$.gilvifrons stopped moving and eating and a pupal stage took place which lasted for 3.73 and 4.47 days as male and female pupae, respectively (Table 1 ).

In general, male immatures completed its life cycle before female immatures where the life cycle averaged 17.70 and 19.90 days for male and female, respectively.

Similar results were obtained by Janardan and Ray (1977) who found the life cycle of an unidentified species of the genus Stethorus durated 14 days at $30{ }^{\circ} \mathrm{C}$, while Puttaswamy and Channa (1977) found that S. pauperculus (Weise) larvae lasted 7.63 days and had 4 larval instar.

Also, Mridul and Badal (2002) noticed that there were 4 larval instars for $S$.gilvifrons fed on Oligonychus coffee Neither where it completed its life cycle in 16.33 days under laboratory conditions. Moreover, Ragkou et al. (2004), found that the first, second, third and fourth larval instars of $S$. punctillum fed voraciously on an average of 19.56, 14.43, 21.90 and 18.40 T. urticae nymphs, respectively.

From the previous results it can be concluded that immature stages of Stethorus species have the ability to feed successfully and consume a considerable number of Tetranychus mite individuals. Accordingly, Khan et al., (2002) stated that the predatory ladybird beetle $S$. vagana (Blackbourn) is one of the best biological agents of $T$. urticae which should be produced commercially. 
J. Agric. Sci. Mansoura Univ., 34 (9), September, 2009 
Nassar, O. A. et al.

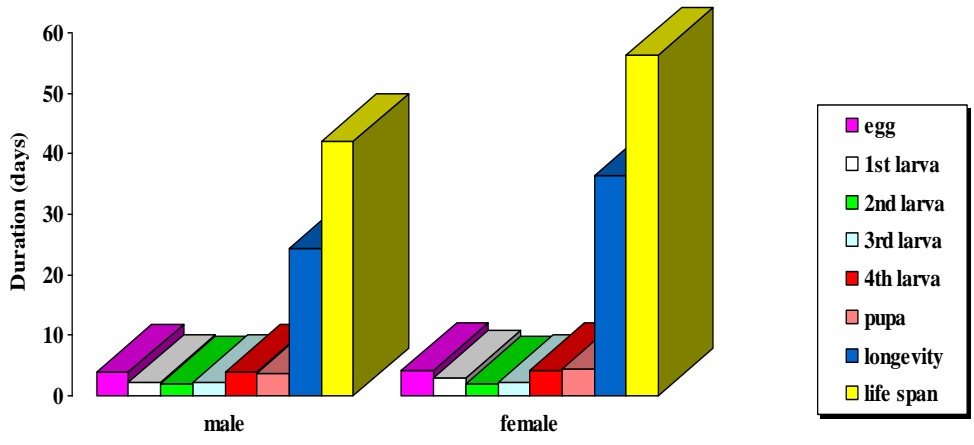

Fig 3 : Duration (days) of immatures and adult male and female of Stethorus gilvifrons fed on Tetranychus urticae nymphs at $25 \mathrm{C}$.

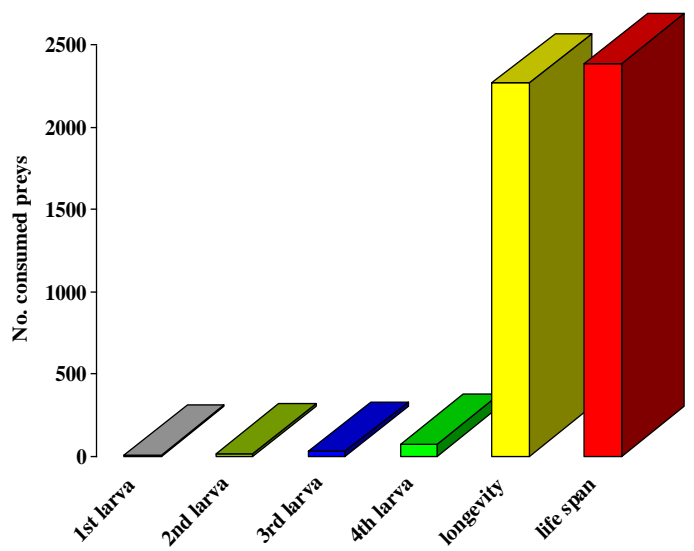
$\square$ 1st larva
$\square$ 2nd larva
a 3rd larva
$\square$ 4th larva
$\square$ longevity
$\square$ life span

Fig 4 : Total number of Tetranychus urticae nymphs consumed by larval instars and adult females of Stethorus gilviforns at $25 \mathrm{oC}$

Concerning adulthood, data in Table 1 and Fig 3 showed that male lived for a shorter time than female. Male and female longevity were 24.33 and 36.46 days, respectively. Female insect passed through a preoviposition period of about 3.46 days, during which it consumed 161.66 prey nymphs with a daily rate of 46.22 individuals before starting to lay eggs. During an average of 25.20 of oviposition period, adult female attacked more prey (1744.53 prey) needed for egg deposition, Table (2) showed that adult female 
of $S$.gilvifrons, which lived 36.46 days, consumed a total number of 2267.13 T. urticae nymphs / female (Fig 4 ). This meant that adult female consumed nearly $95 \%$ of the total number of consumed prey individuals during its whole life span. Also, ovipositing female needed about $76.95 \%$ from the total number of consumed prey in its adulthood.

Similar results were obtained by Roy et al., (2003) who reared S. punctillum on T. mcdanicli and found that its oviposition period lasted 21.10 days at $28{ }^{\circ} \mathrm{C}$. On the other hand, Kasap and Aktung (2003) found that adult female and male of $S$. punctillum fed on $T$. viennesis lived for 50.63 and 34.87 days at $25^{\circ} \mathrm{C}$ and $60 \% \mathrm{RH}$., respectively.

Concerning life table parameters of the predatory lady bird beetle $S$.gilvifrons, data in Table (3) and (Fig 5) clearly indicated that the survivorship curve showed that $L x$ value followed I pattern in which survival rate at $25{ }^{\circ}$ Cwas nearly $100 \%$ Fig. (5). Kishimoto (2003) mentioned that survivorship of Stethorus species was mainly affected by prey species. He found that Amphitetranychus viennensis was the most favorable prey for $S$. japnicus in Japan. In particularly, most predatory larvae reared on Panonychus mori eggs died during the first larval instar and only $10 \%$ of these larvae developed to pupae.

The mean generation time $(T)$ of $S$.gilvifrons averaged 30.41 days. Also, Kasap and Aktug (2003) found that (T) time of $S$. punctillum fed on $T$. viennesis was 30.8 days when reared at $25^{\circ} \mathrm{C}$ and $60 \% \mathrm{RH}$.

Concerning egg production, data showed that the net reproductive rate $\left(R_{0}\right)$ was 49.53 and the intrinsic rate of natural increase $\left(r^{m}\right)$ was 0.12 (Table 8), the finite rate of increase $\mathrm{e}^{\mathrm{rm}}(\lambda)$ was 1.13 .

Similar results were previously obtained by Roy et al., (2003) who found that $\left(\mathrm{r}^{\mathrm{m}}\right)$ value of $S$. punctillum was 1.19 , while it was 0.15 for the same species fed on T. viennensis (Kasap and Aktug. 2003).

On the other hand, Mori et al., (2005) found that $\left(\mathrm{r}^{\mathrm{m}}\right)$ value of $S$. japonicus fed on $T$. urticae eggs was 0.15 at $25^{\circ} \mathrm{C}$. and $\left(R_{0}\right)$ value was 270.49 , (T) time was 51.10 days and the finite rate of increase $e^{r m}(\lambda)$ was 1.169.

From the previous results it can be concluded that the ladybird beetles belonging to the genus Stethorus are obligate predators of tetranychid mites. Therefore, it is highly recommended to know more information about its biology and ecology in order to broaden over options for its potential use as a biocontrol agent.

Table (3) : Life table parameters of Stethorus gilvifrons fed on immature of T. urticae at $25^{\circ} \mathrm{C}$ and $70 \% \mathrm{RH}$.

\begin{tabular}{|c|c|c|c|c|}
\hline $\begin{array}{c}\text { Mean Total } \\
\text { Fecundity }\end{array}$ & $\begin{array}{c}\text { Mean } \\
\text { Generation } \\
\text { Time ( T })\end{array}$ & $\begin{array}{c}\text { Net } \\
\text { Reproductive } \\
\text { Rate }\left(\mathbf{R}_{\mathbf{0}}\right)\end{array}$ & $\begin{array}{c}\text { Intrinsic Rate } \\
\text { of Increase } \\
\left(\mathbf{r}^{\mathbf{m}}\right)\end{array}$ & $\begin{array}{c}\text { Finite Rate of } \\
\text { Increase }\left(\mathbf{e}^{\mathbf{r m}}\right)\end{array}$ \\
\hline 115.26 & 30.41 & 49.53 & 0.12 & 1.13 \\
\hline
\end{tabular}




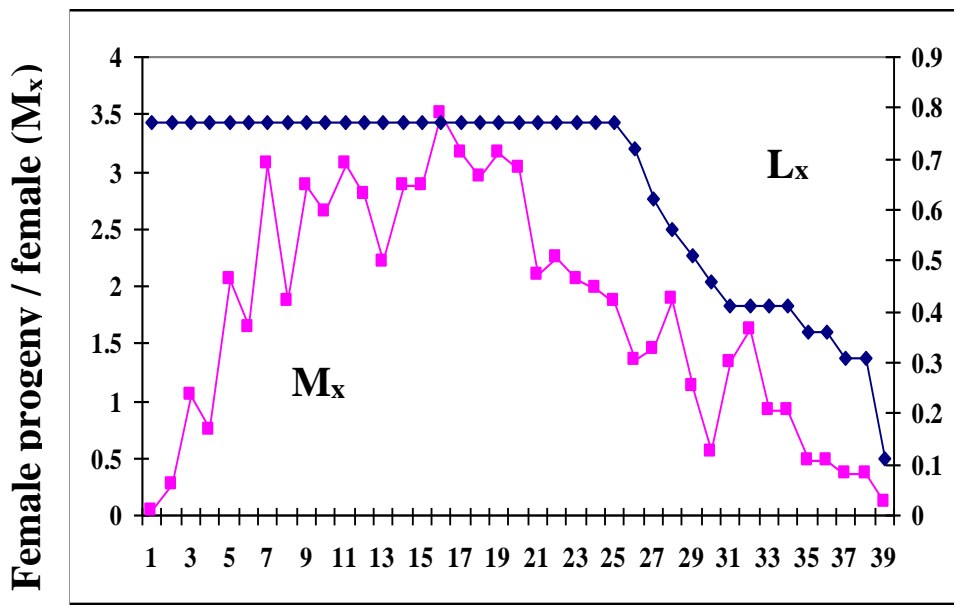

Fig. (5): Age - specific fecundity $\left(M_{x}\right)$ and survivorship $\left(L_{x}\right)$ of Stethorus gilvifrons provided with of $T$. urticae immature at $25{ }^{\circ} \mathrm{C}$.

\section{REFERENCES}

Abou-Setta M.M. and Childers C.C. (1986). Life 48: a BASIC computer program to calculate life tableparameters for an insect or mite species. Fla. Entomol. 69(4): 690-697.

Bailey, P. and Caon, G. (1986).Predators on two-spotted mite, Tetranychus urticae Koch (Acarina:Tetranychidae) by Haplothrips victoriensis Bagnall (Thysanoptera: Phlaeothripidae) and Stethorus nigripes Kapur (Coleoptera: Coccinellidae) on seed lucerne crops in South Australia. Aust. J. Zool. 34:515-525.

Birch, L. C. (1948). The intrinsic rate of natural increase of an insect population.J.Anim.Ecol., 17: $15-26$.

Felland, C.M. and Hull, L.A. (1996).Overwintering of Stethorus punctum (Coleoptera: Coccinellidae) in apple ground cover.Environ. Entomol. 25:972-976.

Geoghiou, G. P. (1990). Overview of insecticide resistance.In Managing Resistance to Agrochemicals (M. B. Green,H. M. LeBaron and W. K. Moberg eds.).AmericanChemical Society Symposium Series 421, pp. 18-41.

Gilstrap, F. E. (1995). Six-spotted thrips: a gift from nature that controls spider mites. In Thrips Biology and Management(B. L. Parker, M. Skinner and T. Lewis eds.).Plenum Press, New York, pp. 305-316.

Janardan, S. and Ray, R. (1977).Stethorus sp. (Coleoptera: Coccinellidae), a predator of Tetranychus neocaledonicus Andre on okra at Varanasi. Acarology Newsletter. No. 4, 5-6. 
Kasap, I. and Aktug, Y. (2003).Studies on the some biological parameters of Stethorus punctillum Weise (Coleoptera: Coccinellidae) feeding on spider mite species (Acarina: Tetranychidae) at laboratory conditions. [Turkish] Turkiye Entomoloji Dergisi. 27: 2, 113-122.

Khan, I.; Spooner-Hart, R.; Bailey, P.; Khalil, S. K. and Ullah, F. (2002).Morphological studies of the predatory ladybird beetle Stethorus vagans (Blackburn) (Coleoptera: Coccinellidae). Journal of Asia-Pacific Entomology. 2002. 5: 1, 29-33. 26 ref.

Kishimoto, H. (2003).Development and oviposition of predacious insects, Stethorus japonicus (Coleoptera: Coccinellidae), Oligota kashmirica benefica (Coleoptera: Staphylinidae), and Scolothrips takahashii (Thysanoptera: Thripidae) reared on different spider mite species (Acari: Tetranychidae).Applied Entomology \& Zoology. 38: 1, 15-21.

Laing, J.E.(1968). Life history and life table of Pytoseiulus persimilis A.-H. acarologia 10(4) : $578-588$.

Mridul Sarmah. and Badal Bhattacharyya. (2002).Biology and feeding potential of Stethorus gilvifrons Mulsant (Coccinellidae: Coleoptera) on tea red spider mite, Oligonychus coffeae Neitner.Shashpa. 9: 1, 23-26.

Puttaswamy. ChannaBasavanna, G. P. (1977).Biology of Stethorus pauperculus Weise (Coleoptera: Coccinellidae), a predator of mites. Mysore Journal of Agricultural Sciences. 11: 1, 81-89.

Ragkou, V. S. ; Athanassiou, C. G.; Kavallieratos, N. G. and Tomanovic, Z. (2004).Daily consumption and predation rate of different Stethorus punctillum instars feeding on Tetranychus urticae. Phytoparasitica. 32: 2, 154-159.

Roy, M. ; Brodeur, J. and Cloutier, C. (2003).Effect of temperature on intrinsic rates of natural increase $(\mathrm{rm})$ of a coccinellid and its spider mite prey.BioControl. 48: 1, 57-72.

Rott, A. S. and Ponsonby, D. J. (2000).The effects of temperature, relative humidity and host plant on the behaviour of Stethorus punctillum as a predator of the two-spotted spider mite, Tetranychus urticae. BioControl. 45: 2, 155-164.

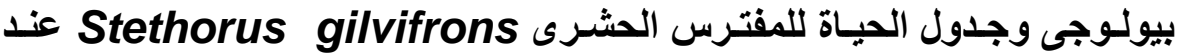

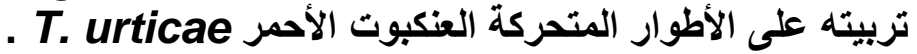

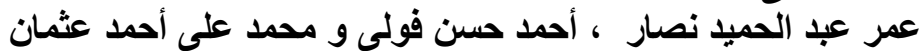

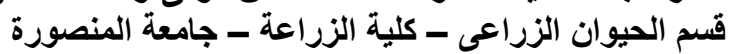

تمت تربية المفترس الحشرى Stethorus gilvifrons على حوريات العنكبوت الأحمر ذور

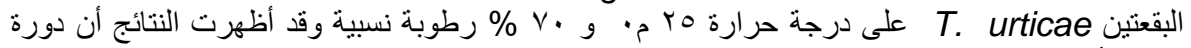

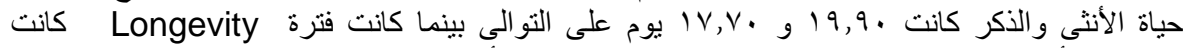
T

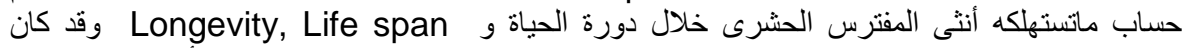

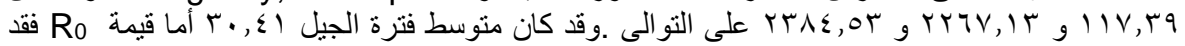
كانت
} 
Table (1): Duration (in days) of developmental stages and adult of Stethorus gilvifrons fed on immature of Tetranychus urticae ( koch ) at $25^{\circ} \mathrm{C}$ and $70 \% \mathrm{RH}$. .

\begin{tabular}{|c|c|c|c|c|c|c|c|}
\hline \multirow[b]{2}{*}{ Sex } & \multirow[b]{2}{*}{ Egg } & \multicolumn{5}{|c|}{ developmental stages } & \multirow[b]{2}{*}{ Life cycle } \\
\hline & & 1 st. larva & 2 nd. Larva & 3 th. Larva & 4 th. Larva & Pupa & \\
\hline$\hat{0}^{2}$ & $3.87 \pm 0.19$ & $2.2 \pm 0.10$ & $1.87 \pm 0.09$ & $2.20 \pm 0.11$ & $3.87 \pm 0.19$ & $3.73 \pm 0.15$ & $17.70 \pm 0.28$ \\
\hline Q & $4.07 \pm 0.11$ & $2.93 \pm 0.18$ & $2.00 \pm 0.14$ & $2.33 \pm 0.13$ & $4.13 \pm 0.21$ & $4.47 \pm 0.21$ & $19.90 \pm 0.31$ \\
\hline
\end{tabular}

\begin{tabular}{|c|c|c|c|c|c|c|c|}
\hline \multirow[t]{2}{*}{ Sex } & \multicolumn{5}{|c|}{ Adults } & Total no. eggs & Daily rate \\
\hline & Preoviposition & Oviposition & Postoviposition & Longevity & Life span & & \\
\hline $0^{\pi}$ & ------------- & ------------- & ------------- & $24.33 \pm 0.90$ & $42.06 \pm 1.04$ & & \\
\hline of & $3.46 \pm 0.29$ & $25.20 \pm 1.52$ & $7.80 \pm 1.14$ & $36.46 \pm 2.30$ & $56.40 \pm 2.29$ & $115.26 \pm 4.23$ & 4.57 \\
\hline
\end{tabular}

\pm SE : Standard errors.

Table (2) : Number of consumed Tetranychus urticae ( koch ) immature preyed by larva and adult females of Stethorus gilvifrons at $25^{\circ} \mathrm{C}$ and $70 \% \mathrm{RH}$. .

\begin{tabular}{|c|c|c|c|c|c|c|c|c|c|c|c|}
\hline \multicolumn{12}{|c|}{ Developmental stages } \\
\hline \multicolumn{2}{|c|}{1 st. larva } & \multicolumn{2}{|c|}{2 nd. Larva } & \multicolumn{2}{|c|}{3 th. Larva } & \multicolumn{2}{|c|}{4 th. Larva } & \multicolumn{2}{|c|}{ Pupa } & $\mathbf{T}$ & D \\
\hline $\mathbf{T}$ & D & $\mathbf{T}$ & D & $\mathbf{T}$ & D & $\mathrm{T}$ & D & $\mathbf{T}$ & D & $11739+1409$ & 589 \\
\hline $7.73 \pm 0.58$ & 2.64 & $14.8 \pm 1.28$ & 7.40 & $25.46 \pm 1.38$ & 10.92 & $69.40 \pm 5.79$ & 16.80 & ----- & ב----י & $117.39 \pm 14.09$ & 3.89 \\
\hline
\end{tabular}

\begin{tabular}{|c|c|c|c|c|c|c|c|c|c|}
\hline \multicolumn{10}{|c|}{ Adult stages } \\
\hline \multicolumn{2}{|c|}{ Preoviposition } & \multicolumn{2}{|c|}{ Oviposition } & \multicolumn{2}{|c|}{ Postoviposition } & \multicolumn{2}{|c|}{ Longevity } & \multicolumn{2}{|l|}{ Life span } \\
\hline$T$ & D & $T$ & D & $\mathbf{T}$ & D & $\mathbf{T}$ & D & $\mathbf{T}$ & D \\
\hline $161.66 \pm 14.09$ & 46.72 & $1744.53 \pm 96.98$ & 69.22 & $360.933 \pm 50.28$ & 46.27 & $2267.13 \pm 126.37$ & 62.18 & $2384.53 \pm 128.54$ & 42.27 \\
\hline
\end{tabular}

